\title{
Determinants of Essential Newborn Care Practice Among Nurses and Midwives Working at Public Health Facilities in Wolayta Zone, Southern Ethiopia: Observational Study
}

\author{
Aseb Arba ${ }^{1^{*}}$, Zerihun Zana ${ }^{2}$, Addisu Alemayehu ${ }^{3}$ and Zeleke Aschalew \\ ${ }^{1}$ Wolaita Sodo University, College of Medicine and Health Sciences, School of Nursing, Ethiopia \\ ${ }^{2}$ Wolaita Zone, Damot Sore Woreda Health Office, Maternal and Child Health Unit, Ethiopia \\ ${ }^{3}$ Arba Minch University, College of Medicine and Health Sciences, School of Nursing, Ethiopia
}

\section{Abstract}

Background: Essential Newborn Care is the care given to the newborn infant following birth within the delivery room by skilled personnel. Immediate and proper essential newborn care provision is important for survival, growth and development of a newborn. In spite of its essentiality, most health care professionals do not practice recommendation of World Health Organization. Therefore, this study was aimed to assess magnitude and factors associated with essential newborn care practice among nurses and midwives working in maternal and child health case team at public health facilities of Wolayta Zone, Southern Ethiopia, 2019.

Methods: Institution based cross sectional study design was conducted from March to October, 2019. Data was collected by using pretested self-administered questionnaire and observation check list. 36 public health facilities were selected by using simple random sampling technique from 73 health facilities. From these, all (218) nurses and midwives who were working in delivery unit from selected facilities were participated in the study. The collected data was entered into Epi data 3.02 and exported to SPSS version 22 for analysis. The result is presented by using frequency and proportions table. Statistical significance was declared at $95 \% \mathrm{CI}, \mathrm{AOR}$ and $\mathrm{p}$-value $\leq 0.05$ in the multivariate analysis in binary logistic regression.

Result: Magnitude of good practice on essential newborn care was $44.4 \%$. Getting in-service training $(\mathrm{AOR}=2.768,95 \% \mathrm{CI}: 1.25,6.13)$, availability of equipment (AOR=3.44, 95\% CI: 1.64, 7.21), knowledge on essential newborn care $(\mathrm{AOR}=3.53,95 \% \mathrm{CI}: 1.75,7.09)$, type of facility ( $\mathrm{AOR}=0.23,95 \% \mathrm{CI}$ : $0.097,0.55)$ and experience of working in delivery unit ( $\mathrm{AOR}=2.582,95 \% \mathrm{CI}$ : $1.198,5.566)$ were factors significantly associated with proper practice of essential newborn care.

Conclusion: The study participants had poor practice on some components of essential newborn care in the study area. The type of facility especially those working in health center had poor practice than those in hospital, availability of equipment and knowledge on essential newborn care were variables independently affecting proper practice of essential newborn care. Therefore; we recommend staff motivation; strengthening training, provision of continuous education, close supervision, providing required equipment and supplies to facility managers, $\mathrm{MCH}$ department head, zonal health department and Woreda health office and non-governmental organizations who were working on maternal and child health.

\section{Introduction}

Essential Newborn Care is the care given to the newborn infant following birth within the delivery room by skilled personnel. Birth is a major challenge to the newborn to negotiate successfully from intrauterine to extra uterine life. This transition from intrauterine to extra uterine life is dramatic one and demands considerable and effective physiological alterations by the baby in order to ensure survival. Immediate proper care of newborn is important for survival, growth and development of a newborn [1,2]. This immediate care time is crucial time to the babies for later wellbeing and adaptation. Skilled care during labor and childbirth with prompt management of complications alone can prevent about $50 \%$ of newborn mortality. Combined with adequate newborn care in the postnatal period, $75 \%$ of current newborn deaths can be prevented. It is a comprehensive strategy designed to improve the health of newborns [3-5].

The precise timing of clamping and cutting the umbilical cord is important to transfer from the placenta of about $80 \mathrm{ml}$ of blood at 1 minute after birth, reaching about $100 \mathrm{ml}$ at 3 minutes after birth. Clean cord care which is very important in preventing early neonatal infections. These more volumes of blood can supply extra iron amounting to $40-50 \mathrm{mg} / \mathrm{kg}$ of body weight $[6,7]$.

Newborns are most vulnerable during the first hours and days of life, yet this critical window of opportunity is being missed [3]. Globally 2.5 million children died in the first month of life at an average rate of 18 deaths per 1,000 live births in 2017 . There are approximately 7000 newborn deaths every day, amounting to $47 \%$ of all child deaths under the age of 5 -years, up from $40 \%$ in 1990 . The world has made substantial progress in child survival since 1990. Globally, the number

"Corresponding Author: Aseb Arba, Wolaita Sodo University, College of Medicine and Health Sciences, Ethiopia, Po Box 200, Phone: +251916038833; E-mail: 40aseb@gmail.com

Citation: Arba A, Zana Z, Alemayehu A, Aschalew Z (2020) Determinants of Essential Newborn Care Practice Among Nurses and Midwives Working at Public Health Facilities in Wolayta Zone, Southern Ethiopia: Observational Study. Int J Pediatr Neonat Care 6: 168. doi: https://doi.org/10.15344/2455-2364/2020/168

Copyright: (C) 2020 Arba et al. This is an open-access article distributed under the terms of the Creative Commons Attribution License, which permits unrestricted use, distribution, and reproduction in any medium, provided the original author and source are credited. 
Citation: Arba A, Zana Z, Alemayehu A, Aschalew Z (2020) Determinants of Essential Newborn Care Practice Among Nurses and Midwives Working at Public Health Facilities in Wolayta Zone, Southern Ethiopia: Observational Study. Int J Pediatr Neonat Care 6: 168. doi: https://doi.org/10.15344/2455-2364/2020/168

Page 2 of 8

of neonatal deaths declined from 5 million in 1990 to 2.5 million in 2017. However, the decline in neonatal mortality from 1990 to 2017 has been slower than that of post-neonatal under-5 mortality: $51 \%$ compared with $62 \%$ globally [2].

Despite promotion of ENC as one strategy for improving newborn health outcomes, the standardized procedure for providing ENC is not fully practiced [8]. A study conducted in eastern Uganda on using the three delays model to understand why newborn babies die showed that neonatal mortality autopsies indicated that the low levels of knowledge among health workers regarding newborn care as a major determinant of neonatal death [10]. Evidence shows that initiating breastfeeding within one hour of birth reduces the neonatal mortality by $44 \%$, recent data show that worldwide less than half of newborn babies receive the benefits of breastfeeding per standard [3].

In Africa a cross-sectional observational assessment of quality of newborn care in health facilities across six sub-Saharan African countries shows that those immediate dried baby with towel were $79 \%$, cut cord with clean blade were $94 \%$, initiated breastfeeding with in the first one hour were $43 \%$, and ties/clamp cord when pulsation stop or 2-3min after birth were 65\% [13]. Study conducted in Sudan Khartoum on immediate care of the newborn showed poor practices on immediate care of the newborn [14]. Study conducted on essential newborn care in Bamako, Mali showed that the dosage of vitamin K was poorly known by the staff that was $18.9 \%$ and $17.2 \%$ among midwives nurses respectively [15].

In Ethiopia, a cross-sectional national facility based observational surveys conducted on maternal and newborn care practices at hospitals shows that immediate essential newborn care is only $18 \%$ $[9,15,16,24]$. A study conducted in Jimma zone on knowledge and practice of essential newborn care among nurses and midwives showed that $(48.9 \%)$ of respondents had poor practice on essential newborn care [9]. The Study conducted in India on assessment of Essential Newborn Care Services in secondary-level facilities pointed out the overall average skill score was $34 \%$. However, the average practice score for doctors were $31 \%$ and for nursing staff was $35 \%$ [27].

A study conducted in Tigray Eastern zone on knowledge and practice of immediate newborn care among midwives showed that (47.6\%) of respondents had poor practice on essential newborn care [26]. A study conducted in Bahir Dar city on knowledge and practice of immediate newborn care among health professionals showed that $40.3 \%$ of respondents had poor practice on essential newborn care [8]. Taking this situation into account, the Ethiopian government collaborating with its partners has launched various initiatives for improving knowledge and skill of health care providers through training health care provider on ENC, equipping health facility with staffs and equipment for provision of essential newborn care $[2,3]$.

Despite this implementation of neonatal mortality rate reduction activities, neonatal death remained stable at 37 deaths per 1,000 live births in the 2011, and 29 deaths per 1,000 live births in 2016 EDHS survey. Over the past 16 years, neonatal mortality declined only by $20 \%[17,18]$. According to goal set in number 3 of sustainable development, United Nation globally aims to end the preventable deaths of newborns from 22 deaths per 1000 live births to 12 deaths per 1000 live births by 2030 [4-7,10]. The current Ethiopian situation of Newborn mortality is far away from UN targets.
Despite all these efforts, neonates face problems after delivery in many public health facilities of Wolaita Zone. So, this study aims to assess the practice gaps of health care provides on essential newborn care and to recommend solutions on the identified gaps to the program managers, policy makers and program implementors. Because similar study was not conducted in my study area before, so this study was carried out to identify gaps on practice of essential newborn care.

\section{Objectives of the Study}

1. To determine magnitude of essential newborn care practice among Nurses and midwives working in $\mathrm{MCH}$ case team at public health facilities of Wolayta Zone, 2019.

2. To identify factors associated with essential newborn care practice among Nurses and Midwives working in $\mathrm{MCH}$ case team at public health facilities of Wolayta Zone, 2019.

\section{Methods and Materials}

\section{Study setting and period}

The study was conducted in public health facilities in Wolayta zone from March to April, 2019. Wolayta zone is one of the 14 zones in Southern Nations Nationalities and Peoples Region (SNNPR), Ethiopia. In the zone, there are currently 5 governmental hospitals and 2 nongovernmental hospitals, 68 health centers post and 342 health. Totally, there are 406 midwives and nurses who are working in $\mathrm{MCH}$ case team at public health facilities of Wolayta Zone.

\section{Study design}

Health facility based cross-sectional study with quantitative and non-participatory observational method of was used.

\section{Population}

\section{Source population}

All nurses and midwives who were working in $\mathrm{MCH}$ case team at public health facilities of Wolayta Zone during data collection period were source population.

\section{Study population}

All nurses and midwives who were working in delivery and postnatal care unit in selected public health facilities of Wolayta Zone during data collection period were considered as study population.

\section{Inclusion and exclusion criteria}

All midwives and nurses who work in labor and delivery unit in selected public health facilities at the time of data collection were included. Student nurses and midwives and those who were in annual live were excluded from study.

\section{Sample size determination}

Sample size was calculated for first and second objectives taking the following assumptions: $\mathrm{P}=$ magnitude of practice is $51.1 \%$ from study conducted on essential newborn care in Jimma zone [9]; $\mathrm{Z} \alpha / 2=$ critical value at $95 \%$ confidence level of certainty (1.96); $d=$ the margin of 
Citation: Arba A, Zana Z, Alemayehu A, Aschalew Z (2020) Determinants of Essential Newborn Care Practice Among Nurses and Midwives Working at Public Health Facilities in Wolayta Zone, Southern Ethiopia: Observational Study. Int J Pediatr Neonat Care 6: 168. doi: https://doi.org/10.15344/2455-2364/2020/168

Page 3 of 8

error or accepted error between the sample and the population $=5 \%$; and sample size calculation was made taking out come in unexposed and adjusted odds ratio to each factor used from different studies, the sample size was calculated by using Epi info version 7.2.1.0 and taking confidence interval of $95 \%$, power $=80 \%$, ratio of exposed to non-exposed as 1:1; and final maximum sample size after adjustment and adding $10 \%$ non-response rate was 218 .

\section{Sampling Procedure}

The study was carried out in randomly selected public health facilities of Wolayta Zone. A 31 health centers were selected by using simple random sampling technique and all public hospitals were included in the study. Finally all nurses and midwives who are working in labor and delivery unit in selected public health facilities were enrolled in the study.

\section{Study Variables}

\section{Dependent variable}

1. Practice of essential newborn care.

\section{Independent variables}

1. Socio-economic factors: sex, age, income level, marital status.

2. Personal factors: educational status, years of experience, training, knowledge, type of profession, interest to work in delivery unit.

3. Institutional factors: availability of equipment, presence of guidelines, facility type.

\section{Operational Definition and Definition of Terms}

Essential Newborn Care: is care provided to a newborn immediately after delivery which includes the time between births to 24 hours care and it includes dry and stimulate, evaluate breathing, keep the newborn warm (Prevent hypothermia), initiate breastfeeding in the first one hour, administer eye ointment, administer vitamin $\mathrm{k}$ intramuscularly, weigh the newborn when it is stable and warm, cord care and delay bathing of the baby for 24 hours after birth.

Good knowledge: when the health care provider answers equal to mean or above from 22 knowledge questions.

Poor knowledge: if the health care provider answers below the mean in $22 \mathrm{knowledge}$ questions.

Good practice: if the health care providers perform more than or equal to $70 \%$ the practice procedures in observation.

Poor practice: if the health care providers performs less than $70 \%$ of the practice procedures in observation.

\section{Data Collection Tools and Methods}

\section{Data collection instruments}

Data were collected using interview administered questionnaire and observation check list to get quantitative data. Interviewadministered structured and pre-tested questionnaire was used to get data on variables of respondents and observation check list was used to assess practice of immediate newborn care. Questionnaire and observation checklists were adapted from different literatures and modified by using different WHO guide lines was used to collect data from nurses and midwives on different variables.

\section{Data collectors and data collection procedures}

The data was collected by ten diploma midwives/nurses and five supervisors who have a bachelor degree in Midwifery/nursing with experience were involved in data collection. Training was given for data collectors and supervisor before the pretest on the objective of the study the contents of the questionnaire, observation checklist, and issue related to the confidentiality of the response and the right of the respondents. The non-participatory observation was applied while a nurse or midwife attend delivery and provide essential newborn care. After observation, other variables were asked from nurse or midwife through interview in private room.

\section{Data quality control}

Data quality was controlled through training of data collectors on objectives, questionnaire, and ways of conducting interview and observation. Pretest was conducted in 5\% of sample size in Sodo Christian hospital and Dubo hospital and the necessary arrangements and corrections were made to standardize and ensure its validity. All filled questionnaires were checked for completeness, accuracy, and consistency. Supervision was done by the supervisors and principal investigator throughout the data collection period.

\section{Data processing and analysis}

First data were coded, completeness and consistencies of questionnaires were checked and data entry was made using Epi data 3.02. Then the data were exported to the SPSS statistical package version 22 for further analysis. Before analysis, data were further cleaned for possible errors. Data were presented in frequency, proportions and summary statistics to describe the study variables and factors under study.

Bivariate analysis was carried out to identify variables that are significantly associated with knowledge of immediate new born care. Variables whose $\mathrm{p}$ value $\leq 0.25$ in bivariate analysis were included in multivariate analysis. Then, multivariate analysis was done to identify independent factors by controlling for possible confounders. AOR at $95 \% \mathrm{CI}$ with p-value $\leq 0.05$ were estimated to measure strength of association and variables were interpreted as having statistically significant association when $\mathrm{p} \leq 0.05$ in logistic regression.

\section{Ethical consideration}

Ethical approval letter was taken from research review committee of Arba Minch University College of Medicine and Health Sciences. An official letter from the university was submitted to Wolayta zone health department. Then letters were written from Wolayta Zone health department to respective Woreda health office and hospital. Data was collected after informed written consent was taken from each participating nurse and midwives on whom observation will be made.

Result

\section{Socio-demographic characteristics}

In this study, 216 nurses and midwifes were participated making a response rate of $99.1 \%$. Among these, 174 (80.6\%) were females. 
Citation: Arba A, Zana Z, Alemayehu A, Aschalew Z (2020) Determinants of Essential Newborn Care Practice Among Nurses and Midwives Working at Public Health Facilities in Wolayta Zone, Southern Ethiopia: Observational Study. Int J Pediatr Neonat Care 6: 168. doi: https://doi.org/10.15344/2455-2364/2020/168

Page 4 of 8

The median age of respondents was 26. Regarding profession, 163 (75.5\%) were midwifes and 53 (24.5\%) were nurses. Regarding their educational qualification, $152(70.4 \%)$ were with diploma level of education and 64 (29.6\%) were with Bachelor degree level of education as shown in Table 1.

\begin{tabular}{|l|l|l|l|}
\hline Variables & Category & Frequency & Percent \\
\hline \multirow{3}{*}{ Age } & $20-30$ & 196 & 90.7 \\
\cline { 2 - 4 } & $31-40$ & 20 & 9.3 \\
\hline \multirow{4}{*}{ Sex } & Male & 42 & 19.4 \\
\cline { 2 - 4 } & Female & 174 & 80.6 \\
\hline \multirow{4}{*}{ Marital status } & Never married & 66 & 30.5 \\
\cline { 2 - 4 } & Married & 149 & 69 \\
\cline { 2 - 4 } & Widowed & 1 & 0.5 \\
\hline \multirow{3}{*}{$\begin{array}{l}\text { Educational } \\
\text { qualification }\end{array}$} & Nurse & 53 & 24.5 \\
\cline { 2 - 4 } & Midwife & 163 & 75.5 \\
\hline \multirow{2}{*}{$\begin{array}{l}\text { Monthly income } \\
\text { in Ethiopian birr }\end{array}$} & Diploma & 152 & 70.4 \\
\cline { 2 - 4 } & $2000-2999$ & 42 & 29.6 \\
\cline { 2 - 4 } & $3000-3999$ & 103 & 19.4 \\
\cline { 2 - 4 } & $4000-4999$ & 47 & 21.8 \\
\cline { 2 - 4 } & $>5000$ & 24 & 11.1 \\
\hline
\end{tabular}

Table 1: Socio-demographic characteristics of respondents among midwifes and nurses working in public health facilities of Wolayta zone, Southern Ethiopia, March-April, 2019.

\section{Facility and individual characteristics}

Regarding work experience of study participants, 161 (74.5\%) had less than five years work experience and participants who had greater than six years of work experience in labor and delivery unit were 55 (25.5\%). Among the study participants, 43 (19.9\%) responded that they had no interest to work in delivery room. 148 (68.5\%), 133 (61.6\%) and 128 (59.3\%) of participants responded presence of guide lines on immediate new born care, equipment for newborn care and vaccines and drugs for newborn care at their health institution respectively. Regarding training, 147(68.1\%) of participants got training on ENC as described in Table 2.

\begin{tabular}{|l|l|l|l|}
\hline Variables & Category & Frequency & Percent \\
\hline \multirow{2}{*}{ Type of facility } & Hospital & 54 & 25 \\
\cline { 2 - 4 } & Health center & 162 & 75 \\
\hline \multirow{2}{*}{$\begin{array}{l}\text { Got in service } \\
\text { training }\end{array}$} & Yes & 147 & 68.1 \\
\cline { 2 - 4 } & No & 69 & 31.9 \\
\hline \multirow{2}{*}{$\begin{array}{l}\text { Experience in delivery } \text { (in year) } \\
\text { Interest to work in }\end{array}$} & $<6$ & 161 & 74.5 \\
\cline { 2 - 4 } delivery unit & $\geq 6$ & 55 & 25.5 \\
\hline \multirow{2}{*}{\begin{tabular}{l} 
Presence of guide line \\
\cline { 2 - 4 }
\end{tabular}} & Yes & 173 & 80.1 \\
\cline { 2 - 4 } & No & 43 & 19.9 \\
\hline \multirow{2}{*}{$\begin{array}{l}\text { Availability of } \\
\text { equipment }\end{array}$} & Yes & 133 & 61.6 \\
\cline { 2 - 4 } & No & 68 & 38.4 \\
\hline \multirow{2}{*}{$\begin{array}{l}\text { Availability of drug } \\
\text { and vaccines }\end{array}$} & Yes & 128 & 68.5 \\
\cline { 2 - 4 } & No & 88 & 31.5 \\
\hline
\end{tabular}

Table 2: Facility and individual characteristics of midwives and nurses working in public health facilities of Wolayta zone, Southern Ethiopia, March-April, 2019.
Knowledge on thermal protection, airway clearance and neonatal resuscitation

Regarding hypothermia protection newborn placement immediately after birth, $65.7 \%$ responded that that newborn should kept on the mother's chest/ belly immediately after birth, the rest $34.3 \%$ did not know the recommended place where newborn should be placed immediately after birth. Among respondents, 68(31.4\%) did not respond the recommended time of bathing newborn. Concerning measures to be taken if baby not crying immediately after delivery, $153(70.8 \%)$ of them responded that the correct measure is calling a help and start resuscitation.

Regarding the position of the baby's head to open the airway, $137(63.4 \%)$ of respondents responded that the baby's head should be slightly extended and 59(27.3\%) were responded as flexed position of the head and 20(9.3\%) of them responded as hyper extended position of the head.

\section{Knowledge of breast feeding}

Regarding breast feeding, majority of study participants were aware that initiation of breast feeding after delivery should be taken within the first hours of delivery. When the participants asked about the duration of exclusive breast feeding, 172 (79.6\%) of the respondents knew that the mother should feed breast her baby exclusively for the first six months, but 44 (21.4\%) of the respondents did not know for how long the mother should exclusively breast feed her baby; 3 (1.4\%) responded as less than six month and $41(19 \%)$ responded as for greater than six month shown Figure 1.

\section{Knowledge of prevention of infection on cord care, eye care and care of low birth weight}

From the respondents half of study participants 109 (50.5\%) were aware that the cord of crying baby should be clamped or tied at 2-3 minutes of delivery or after the pulsation of umbilical artery stopped, but $45(20.8 \%), 62(28.7 \%)$ of them responded as that the cord should be clamped or tied immediately after delivery and within 1-2 minutes of delivery respectively. Out of the total respondents, the vast majority, $182(84.2 \%)$ know to use sterile scissor to cut the cord, but only $14(6.5 \%)$ were aware that new surgical blade can also be used to cut the cord whereas few respondents; 20 (9.3\%) mentioned clean scissor. The vast majority, 196 (90.7\%) were aware that silver nitrate/tetracycline can be applied for the treatment of eye infection for newborn but, only 13(6\%) were aware that sterile water can also be used to clean infected eyes.

\section{Knowledge of nurses and midwives on birth weight of newborn child}

About the recommended cares of low birth weight babies, 99 (45.8\%), 137 (63.4\%), $27(12.5 \%)$ and 8 (3.7\%) of participants identified as breast feeding early and frequently, keeping the child warm, infection prevention and bathing often respectively. Participants who have knowledge on prevention of newborn bleeding were 200 (92.6\%) and 109 (50.5\%) have knowledge about the correct dose of Vitamin K to be given to a term newborn shown in Figure 2.

\section{Provider's knowledge on immediate newborn care}

The overall knowledge of nurse and midwife on immediate newborn care in public health facilities of Wolayta zone is 125 (57.9\%) the average knowledge score is $58 \%$ and standard deviation was 0.495 . 
Citation: Arba A, Zana Z, Alemayehu A, Aschalew Z (2020) Determinants of Essential Newborn Care Practice Among Nurses and Midwives Working at Public Health Facilities in Wolayta Zone, Southern Ethiopia: Observational Study. Int J Pediatr Neonat Care 6: 168. doi: https://doi.org/10.15344/2455-2364/2020/168

Page 5 of 8

\section{Essential Newborn care practice among nurses and midwives}

Observations were made on nurses and midwifes while they giving immediate newborn care. Among the total 216 respondents, 44.4\% (95\% CI: $38 \%, 51 \%)$ participants have good immediate newborn care practice as shown in Figure 3.

Specifically 192 (88.9\%) of the participants have properly practice putting a baby on to mother's abdomen immediately after delivery, $185(85.6 \%)$ of the participants place the baby in skin-to-skin contact and on the breast to initiate breastfeeding, $160(74.1 \%)$ of participants apply tetracycline eye ointment and 70 (32.4\%) give Vitamin K IM on anterior mid-thigh. From health worker place identification labels on newborn were 45 (20.8\%). Health workers weigh the baby immediately after birth was 205 (94.9\%) and initiation of breast feeding within one hour was 196 (90.7\%) shown in Table 3.

\section{Bivariate and multivariate analysis result on practice of immediate ENC}

In bivariate analysis, monthly income, type of profession, educational status, experience in delivery unit, type of facility, interest to work in delivery unit, got in service training, availability of BEmONC guidelines, availability of equipment, availability of drug and vaccines and knowledge on ENC were variables with p-vale less than 0.25 ; hence candidate for multivariate analysis.

Among variables entered in multivariable analysis; knowledge on immediate newborn care $(\mathrm{AOR}=3.53,95 \% \mathrm{CI}: 1.75,7.09)$, type of

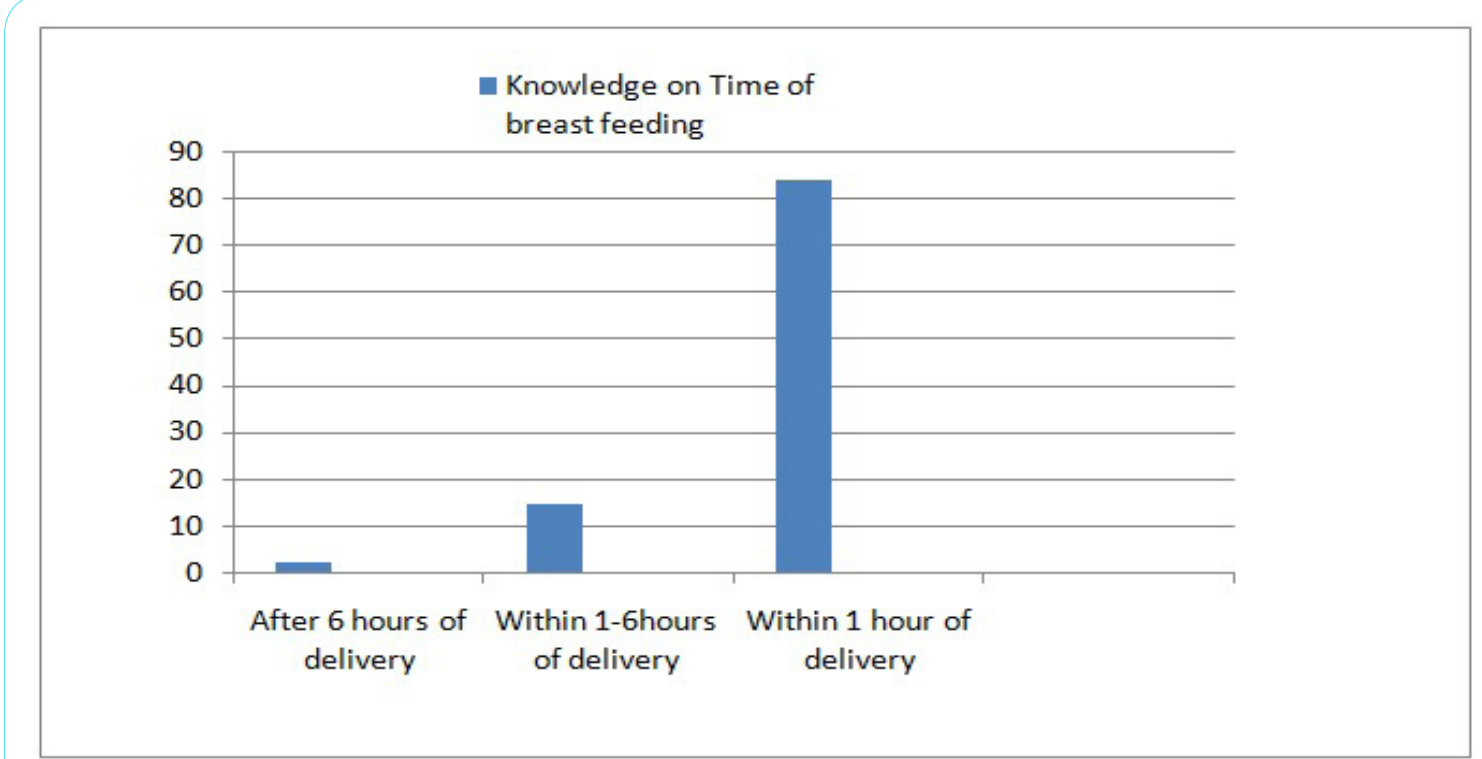

Figure 1: Knowledge of midwives and nurses on time of initiation of breast feeding to immediately born baby at Wolayta zone, southern Ethiopia, March-April, 2019.

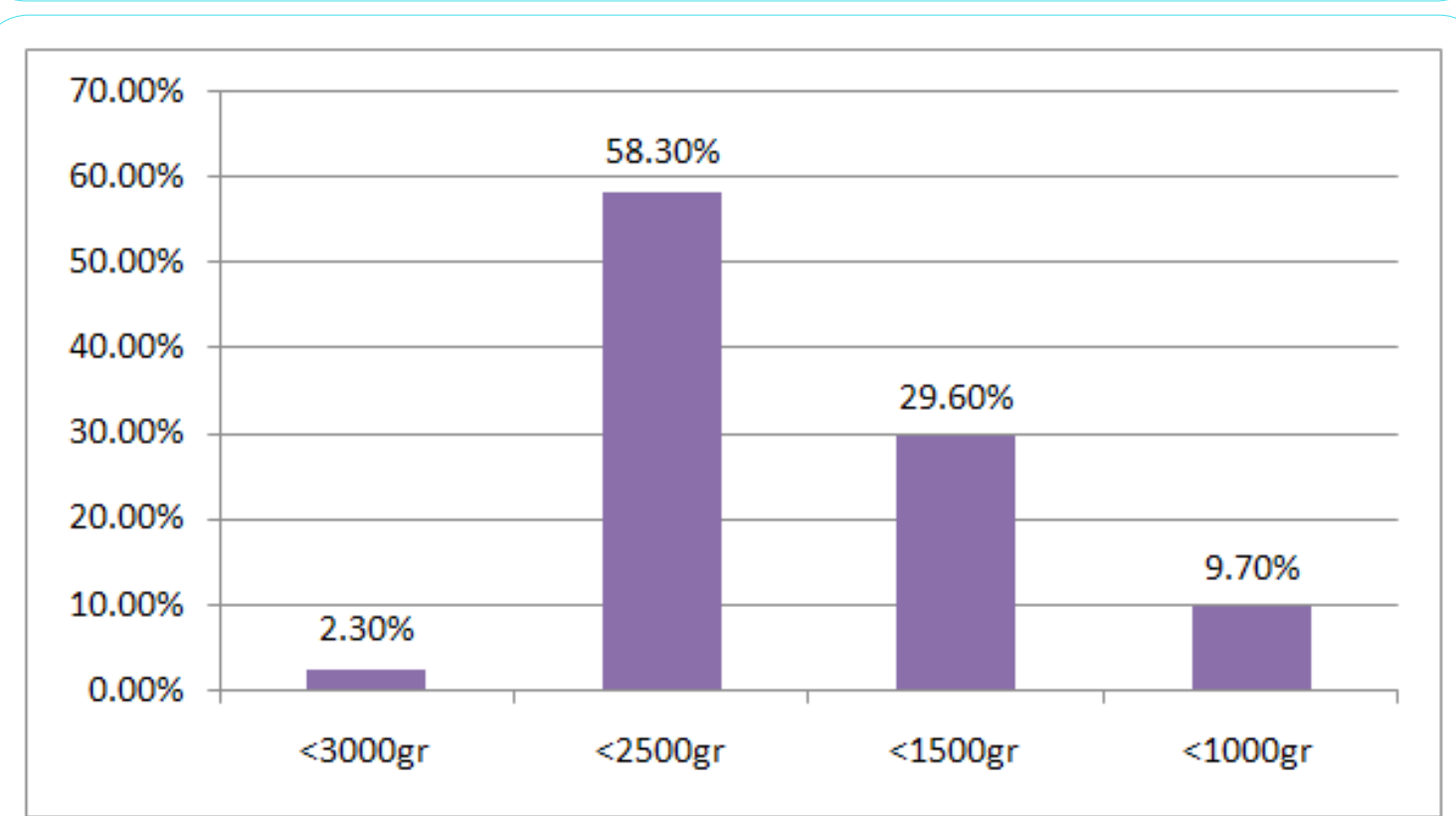

Figure 2: Knowledge of midwives and nurses on definition of low birth weight for newborn child at Wolayta zone, southern Ethiopia, March-April, 2019. 
Citation: Arba A, Zana Z, Alemayehu A, Aschalew Z (2020) Determinants of Essential Newborn Care Practice Among Nurses and Midwives Working at Public Health Facilities in Wolayta Zone, Southern Ethiopia: Observational Study. Int J Pediatr Neonat Care 6: 168. doi: https://doi.org/10.15344/2455-2364/2020/168

Page 6 of 8

facility (AOR=0.23, 95\% CI: $0.097,0.55)$, availability of equipment in health facility for ENC (AOR=3.44, 95\% CI: 1.64, 7.21), getting onjob training $(\mathrm{AOR}=2.768,95 \% \mathrm{CI}: 1.25,6.13)$ and work experience in delivery unit $(\mathrm{AOR}=2.58,95 \% \mathrm{CI}: 1.198,5.566)$ were variables significantly affecting participants' practice on essential newborn care shown in Table 4.

\section{Discussion}

This study was planned to assess magnitude of immediate newborn care practice and to identify associated factors among nurse and midwife in public health facilities of Wolayta zone. Accordingly, magnitude of good practices on immediate care of newborn was $44.4 \%$ (95\% CI: 38\%, 51\%).
This finding goes in line with the study conducted in Khartoum [14] and Jimma zone (51.1\%) [9]. However, this finding is lower compared to study conducted in Tigray eastern zone (72.8\%) [26] and Bahir Dar city (59.7\%) [8]. The difference might be due to variation in set up which is well equipped and areas where there are many nonprofit organizations working with regions, zones and health facilities. Those different organizations provide training and support health facilities with basic facilities.

Regarding factors affecting practice on immediate new born care, knowledge on ENC, training, type of facility, availability of equipment and work experience in delivery unit were identified to be significantly associated with practice on immediate new born care. Knowledge

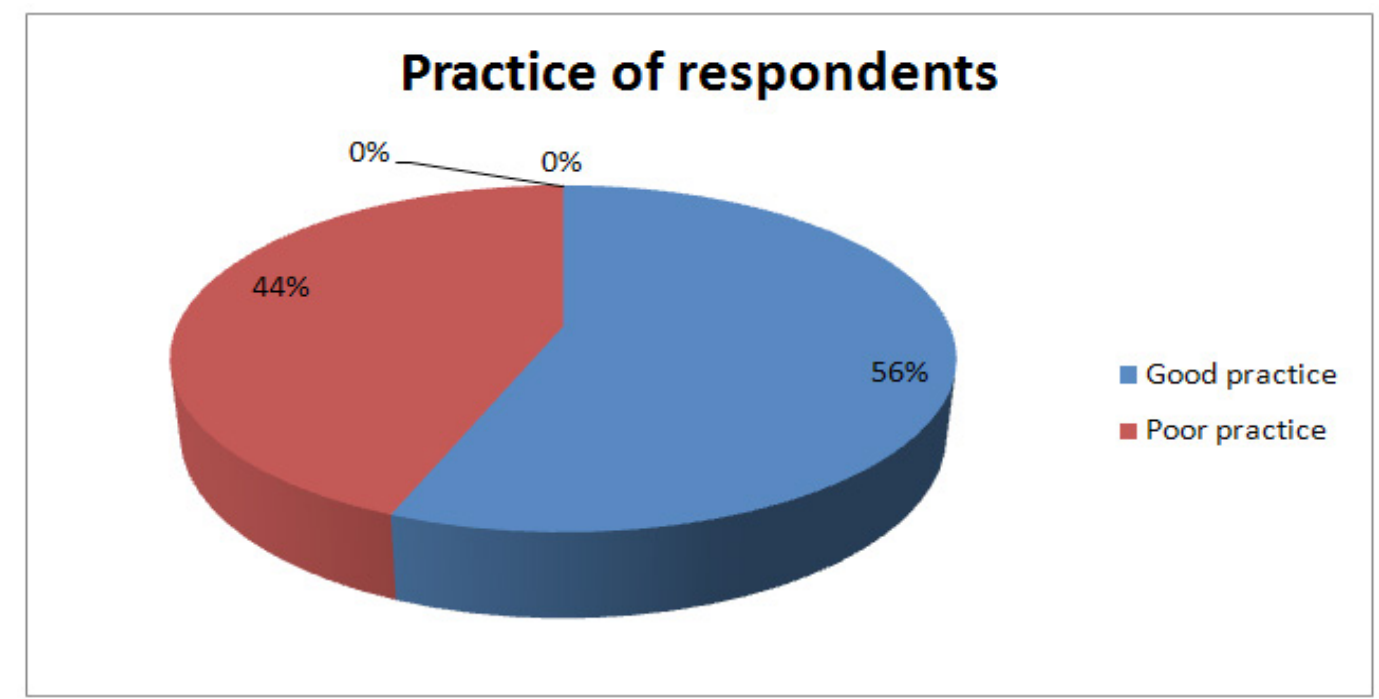

Figure 3: Participants essential new born care practice status in Wolayta zone, southern Ethiopia, March-April, 2019.

\begin{tabular}{|l|l|l|l|}
\hline Variables & Response & Frequency & Percent \\
\hline \multirow{2}{*}{ Dry baby and stimulate breathing } & Yes & 210 & 97.2 \\
\cline { 2 - 4 } & No & 6 & 2.8 \\
\hline \multirow{2}{*}{ Waiting cord cutting for 2-3 minutes } & Yes & 107 & 49.5 \\
\cline { 2 - 4 } & No & 109 & 50.5 \\
\hline \multirow{2}{*}{ Measure body temperature within 1 hour after delivery } & Yes & 24 & 11.1 \\
\cline { 2 - 4 } & No & 192 & 88.9 \\
\hline Use two towels to dry and wrap newborn & Yes & 184 & 85.2 \\
\cline { 2 - 4 } & No & 32 & 14.8 \\
\hline \multirow{3}{*}{ Wipe the eyes and face when the head is delivered } & Yes & 160 & 74.1 \\
\cline { 2 - 4 } & No & 56 & 29.5 \\
\hline Use sterile glove during cord care & Yes & 210 & 97.2 \\
\cline { 2 - 4 } & No & 6 & 2.8 \\
\hline \multirow{3}{*}{ Use of clean mask for deliveries they conducted } & Yes & 83 & 38.4 \\
\cline { 2 - 4 } & No & 133 & 61.6 \\
\hline Use of clean apron for deliveries they conducted & Yes & 191 & 88.4 \\
\cline { 2 - 4 } & No & 25 & 11.6 \\
\hline \multirow{2}{*}{ Record all observations and medications given } & Yes & 195 & 90.3 \\
\cline { 2 - 4 } & No & 21 & 9.7 \\
\hline
\end{tabular}

Table 3: Response of practice related questions among midwifes and nurses working in Public health facilities of Wolayta zone, Southern Ethiopia, March-April, 2019. 
Citation: Arba A, Zana Z, Alemayehu A, Aschalew Z (2020) Determinants of Essential Newborn Care Practice Among Nurses and Midwives Working at Public Health Facilities in Wolayta Zone, Southern Ethiopia: Observational Study. Int J Pediatr Neonat Care 6: 168. doi: https://doi.org/10.15344/2455-2364/2020/168

Page 7 of 8

based practice essential to minimize errors while giving care to newborn. Nurses and midwives with good knowledge are nearly four times more likely to give proper newborn care when compared with those with poor knowledge. This finding was supported by study conducted on knowledge and practice on essential newborn care in Jimma Zone, Ethiopia [29], in Bahir Dar [8], and in Tigray Regional state [23]. This might be due to type of professionals in the health care setting and proof of knowledge is basic to practice.

Availability of equipment in health facility for ENC was significantly associated with participants' practice on essential newborn care. Those health nurses and midwives working in facilities with adequate equipment for ENC were practicing ENC in proper way compared to those working in health facilities having shortage of equipment for newborn care. This study finding is similar with study conducted in Tigray eastern zone [26]. This finding is contrary to the finding from Jimma zone which report that availability of equipment in health facility is statistically insignificant on practice of ENC [29]. The difference might be due to difference in commitment of health system managers across regions and number of nonprofit organizations that provide equipment to health facilities.

The type of facility was significantly associated with participant's practice on essential newborn care. Those participants working in health center were less likely practicing of essential newborn care compared to those participants working in the hospitals. This finding is similar with study conducted in central zone of Tigray region [23] and Tigray eastern zone [26]. This finding is different from the study conducted in Uganda, which shows the type of health facility has no significant association with newborn care practice [25]. This difference may be due to difference in study setting and may be difference in availability of required equipment for essential newborn care.

Training found to be significantly associated with participants' practice on essential newborn care. Participants who had got training on essential newborn care were more likely practiced essential newborn care practice than those who did not trained on essential newborn care. This finding is similar with study conducted in Jimma zone $[9,29]$. This similarity may be due to similarity in study population. Finding from this study shows work experience in delivery unit was significantly associated with practice of essential newborn care. Participants who had served six years or longer were more likely practiced essential newborn care than participants who had served five years or less. However this finding is contrary to the study conducted in Tigrie eastern zone which report that no statistical difference in practice of essential newborn care among different work experience groups [26]. This difference may be due to difference in work experience groups among study populations and may be due to difference in study period.

\begin{tabular}{|c|c|c|c|c|c|c|}
\hline \multirow{2}{*}{$\begin{array}{l}\text { Independent } \\
\text { Variables }\end{array}$} & \multirow[t]{2}{*}{ Category } & \multicolumn{2}{|c|}{ ENC practice } & \multirow[t]{2}{*}{ COR $(95 \% \mathrm{CI})$} & \multirow[t]{2}{*}{ AOR $(95 \% \mathrm{CI})$} & \multirow[t]{2}{*}{ P-value } \\
\hline & & Good & poor & & & \\
\hline \multirow[t]{2}{*}{ Type of Profession } & Midwife & 86 & 77 & $4.80[2.26,10.20]$ & $1.33[0.51,3.45]$ & 0.561 \\
\hline & Nurse & 10 & 43 & 1 & 1 & 1 \\
\hline \multirow{2}{*}{$\begin{array}{l}\text { Educational } \\
\text { qualification }\end{array}$} & Bachelor & 39 & 25 & $2.60[1.43,4.74]$ & $1.90[0.89,4.06]$ & 0.095 \\
\hline & Diploma & 57 & 95 & 1 & 1 & 1 \\
\hline \multirow[t]{2}{*}{ Got training } & Yes & 79 & 68 & $3.55[1.88,6.72]$ & $2.77[1.25,6.13]$ & $0.012^{* *}$ \\
\hline & No & 17 & 52 & 1 & 1 & 1 \\
\hline \multirow{2}{*}{$\begin{array}{l}\text { Interest to work in } \\
\text { delivery unit }\end{array}$} & Yes & 85 & 88 & $2.81[1.33,5.93]$ & $0.92[0.32,2.62]$ & 0.876 \\
\hline & No & 11 & 32 & 1 & 1 & 1 \\
\hline \multirow[t]{2}{*}{ Type of facility } & Health center & 61 & 107 & $0.21[0.10,0.43]$ & $0.23[0.10,0.55]$ & $0.001^{* *}$ \\
\hline & Hospital & 35 & 13 & 1 & 1 & 1 \\
\hline \multirow{2}{*}{$\begin{array}{l}\text { Presence of } \\
\text { BEmONC } \\
\text { guideline }\end{array}$} & Yes & 73 & 60 & $3.17[1.76,5.72]$ & $1.50[0.71,3.20]$ & 0.291 \\
\hline & No & 23 & 60 & 1 & 1 & 1 \\
\hline \multirow{2}{*}{$\begin{array}{l}\text { Availability of } \\
\text { equipment }\end{array}$} & Yes & 80 & 68 & $3.82[2,7]$ & $3.44[1.64,7.21]$ & $0.001^{* *}$ \\
\hline & No & 16 & 52 & 1 & 1 & 1 \\
\hline \multirow{2}{*}{$\begin{array}{l}\text { Availability of } \\
\text { vaccine anddrug }\end{array}$} & Yes & 70 & 58 & $2.88[1.62,5.12]$ & $1.68[0.80,3.54]$ & 0.169 \\
\hline & No & 26 & 62 & 1 & 1 & 1 \\
\hline \multirow{4}{*}{$\begin{array}{l}\text { Monthly } \\
\text { income(ETB) }\end{array}$} & $>5000$ & 14 & 10 & $3.12[1.10,8.86]$ & $0.17[0.17,5.56]$ & 0.980 \\
\hline & $4000-4999$ & 29 & 18 & $3.59[1.49,8.66]$ & $1.06[0.28,3.93]$ & 0.935 \\
\hline & 3000-3999 & 40 & 63 & $1.42[0.66,3.04]$ & $0.82[0.27,2.45]$ & 0.716 \\
\hline & $2000-2999$ & 13 & 29 & 1 & 1 & 1 \\
\hline \multirow{2}{*}{$\begin{array}{l}\text { Experience in } \\
\text { delivery unit }\end{array}$} & $>6$ years & 34 & 21 & $2.59[1.38,4.85]$ & $2.58[1.20,5.57]$ & $0.015^{* *}$ \\
\hline & $0-5$ years & 62 & 99 & 1 & 1 & 1 \\
\hline \multirow{2}{*}{$\begin{array}{l}\text { Knowledge on } \\
\text { ENC }\end{array}$} & Good & 77 & 48 & $6.08[3.27,11.31]$ & $3.53[1.75,7.09]$ & $0.001^{* *}$ \\
\hline & Poor & 19 & 72 & 1 & 1 & 1 \\
\hline
\end{tabular}

Table 4: Bivariate and Multivariate analysis result for factors associated with practice on essential new born care among midwifes and nurses working in Public health facilities of Wolayta zone, Southern Ethiopia, March-April, 2019. 
Citation: Arba A, Zana Z, Alemayehu A, Aschalew Z (2020) Determinants of Essential Newborn Care Practice Among Nurses and Midwives Working at Public Health Facilities in Wolayta Zone, Southern Ethiopia: Observational Study. Int J Pediatr Neonat Care 6: 168. doi: https://doi.org/10.15344/2455-2364/2020/168

Page 8 of 8

\section{Conclusion and Recommendation}

Practice gap exists among midwives and nurses on care given to immediately born baby in the study area. Especially, cord clamping time, consistently administration of Vitamin K, placing identification and using clean mask during attending delivery take lion share of practice gap among midwives and nurses in the study. The managing bodies of health facilities should strive to improve practice of essential new born care through creating training opportunities for staffs working in delivery room.

In addition, the institutions should create strong structure to follow poor practice providing strong supportive supervision system and constructive feedback mechanism. All other concerned bodies that work on $\mathrm{MCH}$ should take part by appraising good performers in taking care of essential new born care through supporting necessary supplies. Further research in the area should consider qualitative method and should involve the whole region.

\section{Competing Interests}

The authors declare that they have no competing interests.

\section{Author's Contributions}

The idea of the study was conceived, designed, write up and initial draft of manuscript was done by Zerihun $\mathrm{Z}$ and Aseb A; whereas Addisu A. and Zeleke A. worked together on methodology, field supervision, and analysis and manuscript review process.

\section{Acknowledgments}

We are very grateful to Arba Minch University College of Medicine and Health Sciences for giving chance and supporting throughout this research project. Our sincere and deepest gratitude goes to administrators of public health facilities for their crucial assistance and facilitation. We would also like to extend our heartfelt appreciation to the study participants for their cooperation.

\section{References}

1. WHO (2017) World Health Organization recommendations on newborn health: guidelines approved by the WHO Guidelines Review Committee. Geneva: World Health Organization.

2. Organization WH (2010) Essential Newborn Care Course. Clinical Practice Workbook.

3. Worku B, Gessessie M (2012) Newborn care training manual, essential new born care for every baby. Federal Ministry of Health Ethiopia EPS.

4. Paul V (2014) Newborn Nursing for facility based care. Learn Guide. Department of pediatrics, AIIMS, New Delhi.

5. Organization WH (2015) WHO Safe Childbirth Checklist Implementation Guide 20 Avenue Appia. Geneva, Switzerland: World Health Organization.

6. BIa MS (2004) National Guidelines for Quality Obstetrics and Perinatal Care Republic of Kenya. Division of Reproductive health.

7. WHO (2018) Newborns: reducing mortality.

8. Yemaneh Y, Dagnachew E (2017) Knowledge and Practice of Immediate New Born Care (Inc.) among Health Professionals in Governmental Health Facilities of Bahir Dar City, North Ethiopia 2016. Quality in Primary Care 25: 360-367.

9. Negussie BB, Hailu FB, Megenta AD (2016) Knowledge and Practice of Essential Newborn Care and Associated Factors among Nurses and Midwives Working at Health Centers in Jimma Zone, Ethiopia. J Nurs Care 7: 446 .
10. Lerberghe WV MA, Matthews Z, Wolfheim C (2005) Make every mother and child count. Geneva.

11. Waiswa P, Kallander K, Peterson S, Tomson G, Pariyo GW, et al. (2010) Using the three delays model to understand why newborn babies die in eastern Uganda. Trop Med Int Health 15: 964-972.

12. Malhotra S, Zodpey SP, Vidyasagaran AL, Sharma K, Raj SS, et al. (2014) Assessment of essential newborn care services in secondary-level facilities from two districts of India. J Health Popul Nutr 32: 130-141.

13. de Graft-Johnson J, Vesel L, Rosen HE, Rawlins B, Abwao S, et al. (2017) Cross-sectional observational assessment of quality of newborn care immediately after birth in health facilities across six sub-Saharan African countries. BMJ Open 7: e014680.

14. Faiza AN (2013) Assessment of knowledge, Attitude and Practices of nurse midwives towards immediate care of the newborn in Khartoum state teaching hospitals. J Am Sci 9: 263-270.

15. Traoré FD, Sylla $M$, Diall $H$, Traoré $M$, Togo $P$, et al. (2018) Knowledge of Health Professionals on Essential Newborn Care in Bamako, Mali. Open Journal of Pediatrics 8: 311-323.

16. Ashebir G, Jim R, David C, Barbara R, Heather R, et al. (2011) Quality of Care for Prevention and Management of Common Maternal and Newborn Complications: A Study of Ethiopia's Hospitals.

17. EPHI (2016) Ethiopian Emergency Obstetric and Newborn Care (EmONC) Assessment.

18. Central Statistical Agency (CSA) and ICF (2016) Ethiopia Demographic and Health Survey 2016. Addis Ababa, Ethiopia, and Rockville, Maryland, USA: CSA and ICF.

19. Millar K, MHTF (2014) Lancet launches every newborn series; Where we have been and where we need to go. Lancet may.

20. Acharya D, Paudel R (2015) Assessment of Critical Knowledge on Materna and Newborn care Services among Primary Level Nurse Mid-wives in Kapilvastu District of Nepal. Kathmandu Univ Med J 13: 351-356.

21. Ayiasi RM, Criel B, Orach CG, Nabiwemba E, Kolsteren P, et al. (2014) Primary healthcare worker knowledge related to prenatal and immediate newborn care: a cross sectional study in Masindi, Uganda. BMC health serv res 14: 65.

22. Faiza ANT (2011) Assessment of knowledge, Attitude and Practices of nurse midwives towards immediate care of the new born In Khartoum state teaching hospitals.

23. Berhe AK, Tinsae F, Gebreegziabher G (2016) Knowledge and practice of immediate newborn care among health care providers in Eastern zone public health facilities, Tigray, Ethiopia, 2016. BMC pediatrics 17: 157.

24. Wondaferash MT (2011) Assessment of Knowledge, Attitude, and Practice about immediate newborn care among health care providers in addis ababa public health centers. Ethiopian Journal of Pediatrics and Child Health 7: 42-79.

25. Ayiasi RM, Criel B, Orach CG, Nabiwemba E, Kolsteren P, et al. (2014) Primary healthcare worker knowledge related to prenatal and immediate newborn care: a cross sectional study in Masindi, Uganda. BMC Health Serv Res 14: 65.

26. Tesfay TG, Rajalakshmi M, Alem GA, Mekonnen HG (2019) Knowledge and practice of immediate new-born care among midwives in eastern zone public health facilities, Tigray, Ethiopia: cross sectional study. 12: 487.

27. Agrawal PK, Agrawal S, Ahmed S, Darmstadt GL, Williams EK, et al. (2012) Effect of knowledge of community health workers on essential newborn health care: A study from rural India Health Health Policy Plan 27: 115-126.

28. Lutwama GW, Roos JH, Dolamo BL (2012) A descriptive study on health workforce performance after decentralisation of health services in Uganda. Hum Resour Health Sci J 10: 41.

29. Bereka B, Balcha F, Demissie A (2016) Assessment of Knowledge and Practice of Essential Newborn Care and Associated Factors among Nurses and Midwives Working at Health Centers in Jimma Zone, Oromia Regional State, South West Of Ethiopia, 2016: Addis Ababa University.

30. Acharya D, Paudel R, Gautam K, Gautam S, Upadhyaya T, et al. (2016) Knowledge of maternal and newborn care among primary level health workers in Kapilvastu district of Nepal. Ann Med Health Sci Res 6: 27-32. 